International Journal of Current Advanced Research

ISSN: O: 2319-6475, ISSN: P: 2319 - 6505, Impact Factor: SJIF: 5.995

Available Online at www.journalijcar.org

Volume 6; Issue 4; April 2017; Page No. 3506-3508

DOI: http://dx.doi.org/10.24327/ijcar.2017.3508.0304

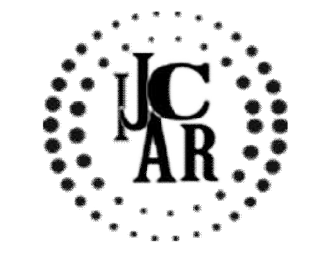

Research Article

\title{
DIET AND LIFESTYLE AFFECTING CONCENTRATION LEVEL-A SURVEY
}

\author{
Simon Chouhan and Gayathri Devi R
}

Saveetha Dental College and Hospitals, Saveetha University, Chennai-600077

\begin{tabular}{l}
\hline A R T I C L E I N F O \\
Article History: \\
Received $20^{\text {th }}$ January, 2017 \\
Received in revised form $10^{\text {th }}$ February, 2017 \\
Accepted $22^{\text {nd }}$ March, 2017 \\
Published online $28^{\text {th }}$ April, 2017
\end{tabular}

Key words:

Diet And Lifestyle, Concentration Level

\begin{abstract}
A B S T R A C T
A diet which is balanced properly is helpful in lowering diseases such as obesity, diabetes etc. This was an online survey which contained questions regarding diet and lifestyle. A group of 100 people were surveyed using a consisting of 13 questions. Results were evaluated for each and every question in pie charts and bar graphs. The results were quite impressive as many had good and controlled diet .This also explains how a individual's diet and lifestyle effect their concentration level. This study was done to know the effects of diet and lifestyle on concentration level.
\end{abstract}

Copyright $₫ 2017$ Simon Chouhan and Gayathri Devi R. This is an open access article distributed under the Creative Commons Attribution License, which permits unrestricted use, distribution, and reproduction in any medium, provided the original work is properly cited.

\section{INTRODUCTION}

A healthy diet is one that helps to maintain or improve overall health. A healthy diet provides the body with essential nutrition: fluid, adequate essential amino acids from protein, essential fatty acids, vitamins minerals and adequate calories.Eating regularly three meals a day helps you to concentrate. A properly balanced diet is also thought to be important for lowering health risks such as obesity, heart disease, type 2 diabetes, hypertension cancer, etc. Diets to promote weight loss are divided into four categories: low fat, low carbohydrate, low calorie and very low calorie. (1). The basic principles of good diets are eat less, move more, eat lots of fruits and vegetables. For additional clarification, a fiveword modifier helps: go easy on junk foods. (2) Eating junk food affects the behavior, cognition and focus. A 2009 study published in the "European Journal of Clinical Nutrition" found that children and adults who indulged in a high junk food diet were more likely to be hyperactive than those who did not. Hyperactive children lack concentration and even they may not be able to concentrate on simple tasks. For adults who eat a diet high in junk food; hyperactivity, a lack of focus and an inability to concentrate could affect your work, your relationships and your lifestyle. Larger brains in humanoids are associated with development of cooking skills, access to food, energy savings and upright walking and running (3) Leptin is synthesised in adipose tissue and send signals to brain to reduce appetite.(4). The brain is highly susceptible to oxidative damage because of its high metabolic load and its abundance of oxidizable material, such as the

*Corresponding author: Simon Chouhan

Saveetha Dental College and Hospitals, Saveetha

University, Chennai-600077 poly-unsaturated fatty acids that form the plasma membranes of neural cells. (5). Alpha lipoic acid has been shown to improve memory deficits in animal models of Alzheimer's disease. (6) and to reduce cognitive decay in a small group of patients with Alzheimer's disease (7) Vitamin E, or $\alpha$ tocopherol, has also been implicated in cognitive performance, as decreasing serum levels of vitamin E were associated with poor memory performance in older individuals (8) Vitamin $\mathrm{E}$ is abundant in vegetable oils, nuts, green leafy vegetables and fortified cereals, and has been shown to extend lifespan and improve mitochondrial function and neurological performance in aging mice (9). Thus Diet, exercise and other aspects of our daily interaction with the environment have the potential to alter our brain health and mental function. (10). The short term effects of consumption of alcohol (ethanol) and other alcoholic beverages- range from a decrease in anxiety and motor skills and euphoria at lower doses to intoxication (drunkenness), stupor, unconsciousness, anterograde amnesia (memory "blackouts"), and central nervous system depression at higher doses). However, animal and human studies suggest that the quantity and quality of sleep have a profound impact on learning and memory. Research suggests that sleep helps learning and memory in two distinct ways. First, a sleep-deprived person cannot focus attention optimally and therefore cannot learn efficiently. Second, sleep itself has a role in the consolidation of memory, which is essential for learning new information. (11).

\section{MATERIALS AND METHODS}

The survey was carried out by online, a generalised questionnaire was prepared with supporting articles and questionnaire contained about 13 questions \& it was sent to 
100 people. The questions were thoroughly explained to the participants and data were collected by study are as follows. brain. These specific areas are involved in planning, attention, monitoring and concentration, according to this study which

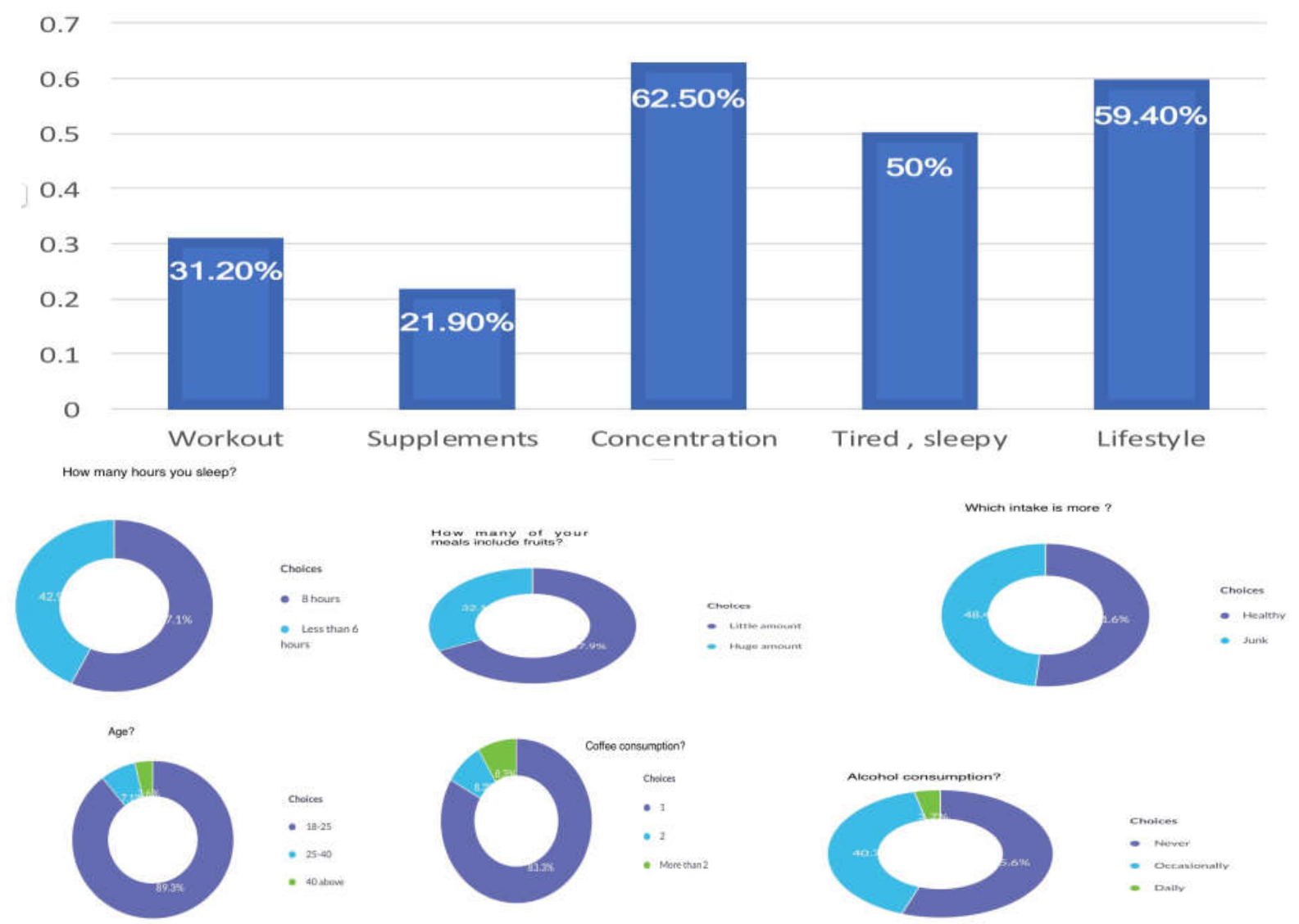

\section{RESULTS AND DISCUSSION}

The results of the survey were collected.The collected datas were analysed and were tabulated.The Results were tabulated in pie charts and bar graphs.More than 100 people responded in the survey out of which $3.6 \%$ belonged to the age of 40 above, $7.1 \%$, belonged to the age between 25 to 40 and 89.3 $.3 \%$ belonged to the age between $18-25$. Participants said that there intake of healthy food was $51.6 \%$ and $48.4 \%$ is of junk food.A study published in the American Journal of Clinical Nutrition in 2011 showed that healthy people who ate junk food for only 5 days performed poorly on cognitive tests that measured attention, speed, and mood. It concluded that eating junk food for just five days regularly can deteriorate your memory (12).87.9\% were having fruits in huge amount.Alcohol and coffee consumption was not too much $.57 .1 \%$ people had 8 hours of sleep on daily basis and $42.9 \%$ people had less than 6 hours of sleep. Sleep deprivation deteriorates accuracy of performance, especially in young subjects.(13)

$62.5 \%$ feel that where they were is a good place to concentrate and $59.4 \%$ were satisfied with their lifestyle. The concentration of alcohol in blood is measured via blood alcohol content (BAC). The amount and circumstances of consumption play a large part in determining the extent of intoxication; for example, eating a heavy meal before alcohol consumption causes alcohol to absorb more slowly. In a 2005 study by Florian Koppelstätter and colleagues at the Medical University at Innsbruck, Austria, fMRI scans determined that caffeine promoted increased activity of the anterior cingulate and the anterior cingulate gyrus in the prefrontal lobe of the was presented at the 2005 meeting of the Radiological Society of North America. In general, low-calorie diets are high in carbohydrates $(55 \%-60 \%$ of total daily energy intake), low in fat $(<30 \%$ of energy intake), and energy-reduced (deficit of $2100-4200 \mathrm{~kJ} / \mathrm{d}$ : minimum of $4200-5040 \mathrm{~kJ} / \mathrm{d}$ for women and $5040-5880 \mathrm{~kJ} / \mathrm{d}$ for men)(1). Although caffeine has been shown to stimulate concentration, there is inconclusive evidence of how long this effect lasts or precisely how it varies in individuals. Sleepiness slows down your thought processes. Scientists measuring sleepiness have found that sleep deprivation leads to lower alertness and concentration. This hampers your ability to perform tasks that require logical reasoning or complex thought. Sleepiness also impairs judgment $31.20 \%$ workout daily. Exercise helps trigger endorphins, which improve the prioritizing functions of the brain. After exercise, your ability to sort out priorities improves, allowing you to block out distractions and better concentrate on the task at hand. Your brain remembers more when your body is active. (14).

\section{CONCLUSION}

With this survey we may conclude that Diet and lifestyle plays a major role in concentration. Also people who want to improve their concentration level, by maintaining their diet can boost it up and see the results. This study may help the society to concentrate on diet thereby improve their concentration level.

\section{References}

1. Strychar I (January 2006). "Diet in the management of weight loss". CMAJ. 174 (1): 56-63. doi:10.1503/ 
cmaj.045037. PMC 1319349<img alt="Freely accessible" $\quad \mathrm{src}=$ "//upload.wikimedia.org/wikipedia/ commons/thumb/6/65/Lock-green.svg/9px-Lockgreen.svg.png" title="Freely accessible" width="9" height="14" data-file-width="512" data-fileheight="813">. PMID 16389240

2. Gibbons A. Paleoanthropology. Food for thought Science. 2007;316:1558-1560.[PubMed]

3. Harvey J. Leptin regulation of neuronal excitability and cognitive function. Curr Opin Pharmacol. 2007;7:643647. [PMC free article] [PubMed]

4. Joseph JA, Shukitt-Hale B, Lau FC. Fruit polyphenols and their effects on neuronal signaling and behavior in senescence. Ann NY Acad Sci. 2007; 1100:470-485. [PubMed]

5. Quinn JF, et al. Chronic dietary $\alpha$-lipoic acid reduces deficits in hippocampal memory of aged Tg2576 mice. Neurobiol Aging. 2007; 28:213-225. [PubMed]

6. Holmquist L, et al. Lipoic acid as a novel treatment for Alzheimer's disease and related dementias. Pharmacol Ther. 2007; 113:154-164. [PubMed]

7. Perkins AJ, et al. Association of antioxidants with memory in a multiethnic elderly sample using the Third National Health and Nutrition Examination Survey. Am J Epidemiol. 1999; 150:37-44. [PubMed]
8. Navarro A, et al. Vitamin $\mathrm{E}$ at high doses improves survival, neurological performance, and brain mitochondrial function in aging male mice. $\mathrm{Am} \mathrm{J}$ Physiol Regul Integr Comp Physiol. 2005; 289:R1392R1399. [PubMed]

9. Vaynman S, Gomez-Pinilla F. Revenge of the "sit": how lifestyle impacts neuronal and cognitive health through molecular systems that interface energy metabolism with neuronal plasticity. J Neurosci Res. 2006; 84:699-715. [PubMed]

10. I Horowitz M, Maddox A, Bochner M, et al. (August 1989). "Relationships between gastric emptying of solid and caloric liquid meals and alcohol absorption". Am. J. Physiol. 257 (2 Pt 1): G291-8. PMID 2764113

11. Pfahler, Eric (21 July 2014). "National Junk Food Day: Pick your favorite unhealthy treats in this poll". WMAR-TV ABC 2 News (Scripps TV Station Group). Retrieved 8 April2015.

12. Brendel DH, Reynolds CF, 3rd, Jennings JR, et al. Sleep stage physiology, mood, and vigilance responses to total sleep deprivation in healthy 80 -year-olds and 20-year-olds. Psychophysiology. 1990; 27:677-85. [PubMed]

13. Richardson CR, Faulkner G, and McDevitt J. et al. Integrating physical activity into mental health services for persons with serious mental illness. Psychiatr Serv. 2005 56:324-331. [PubMed].

\section{How to cite this article:}

Simon Chouhan and Gayathri Devi R (2017) ' Diet And Lifestyle Affecting Concentration Level-A Survey', International Journal of Current Advanced Research, 06(04), pp. 3506-3508.

DOI: http://dx.doi.org/10.24327/ijcar.2017.3508.0304 